\title{
ESTUDO DE MITIGAÇÃO PELO MÉTODO ACELERADO DE REATIVIDADE ÁLCALI- AGREGADO EM CONCRETOS PARA FUNDAÇÕES DE SUBESTAÇÕES E LINHAS DE TRANSMISSÃO NO NORTE DE MINAS GERAIS
}

\author{
M. MUNARETTO COPETTI \\ Engenheira Civil \\ UFSM \\ RS, Brasil \\ marinamunaretto@hotmail.com
}

\author{
P.N. JOHANN KÜLZER \\ Engenheira Civil \\ URI \\ RS, Brasil \\ pnjoahnnk@gmail.com
}

\author{
P. PANNO \\ Engenheira Civil \\ UNIPAMPA \\ RS, Brasil \\ CC.SANTOS \\ Eng $^{\text {a }}$ Civil e Prof ${ }^{a}$ Universitária \\ UFSM \\ RS, Brasil \\ panno.pati@gmail.com cristianecdossantos@hotmail.com
}

\section{RESUMO}

Um dos vários problemas que afetam a durabilidade do concreto é a reação álcali-agregado(RAA), um fenômeno bastante complexo que pode desencadear problemas de nível estrutural e operacional. Dependendo das condições que a estrutura está exposta, esta reação deletéria gera expansões intensas que podem ser observadas em diferentes idades, a partir de sua instalação, dependendo do grau de reatividade do agregado. Com relação as medidas preventivas a serem adotadas com o objetivo de evitar a instalação da RAA estão o estudo preliminar da rocha dos agregados a serem empregados na obra, caracterização química do cimento a ser utilizado na obra. Existem confirmações da existência de RAA logo após o início a construção, porém outros casos envolvem a patologia a longo prazo. No norte de Minas Gerais há incidência relativamente alta em fundações de subestações e linhas de transmissão então esse estudo teve como objetivo a análise dos materiais de cinco concreteiras da região onde se instalará futura obra prevendo medidas fez-se ensaios de Determinação da Mitigação em Barras de Argamassa pelo Método Acelerado de Reatividade ÁlcaliAgregado e posterior estudo de traço que possa a vir ser utilizado na obra com materiais selecionados como cimentos com menores teores de álcalis e sílica ativa. Todos os traços estudados apresentaram desempenho satisfatório no quesito mitigação, mas os traços onde havia CP II E 40 apresentaram desempenho mais eficiente comprovando a ação positiva da pozolana no concreto. Este estudo contribui para reforçarmos a importância do estudo prévio em regiões onde a incidência desse tipo de agregado reativo é comum para evitar futuros problemas.

Palavras-chave: reação álcali-agregado, subestações e linhas de trasmissão, estudo de caso.

\begin{abstract}
One of several problems affecting the durability of concrete is the alkali-aggregate reaction (RAA), a very complex phenomenon that can trigger structural and operational problems. Depending on the conditions to which the structure is exposed, this deleterious reaction generates intense expansions that can be observed at different ages from its installation, depending on the degree of reactivity of the aggregate. Regarding the preventive measures to be adopted in order to avoid the installation of the RAA are the preliminary study of the aggregate rock to be used on site, chemical characterization of the cement to be used on site. There are confirmations of the existence of RAA soon after construction begins, but other cases involve long-term pathology. In the north of Minas Gerais there is a relatively high incidence in substations foundations and transmission lines so this study aimed to analyze the materials of five concrete works in the region where future work will be installed, predicting measures and mitigation determination tests. Mortar by the Accelerated Alkali-Aggregate Reactivity Method and subsequent trace study that may be used on site with selected materials such as cements with lower alkali and active silica contents. All traits studied presented satisfactory performance in the mitigation aspect, but the traits where there was CP II and 40 presented more efficient performance proving the positive action of pozzolan in the concrete.
\end{abstract}

Keywords: alkali-aggregate reaction, substations and transmission lines, case study 


\section{PATOLOGIA DO CONCRETO}

Os fenômenos patológicos habitualmente apresentam manifestação externa característica, a partir da qual se pode ter uma ideia dedutiva quanto à natureza, à origem e aos mecanismos dos fenômenos envolvidos. Pode-se dizer que os problemas patológicos de maior gravidade nas estruturas em concreto armado, especialmente pelo seu evidente risco à integridade da estrutura, são a corrosão da armadura do concreto, as fissuras e as flechas excessivas das peças estruturais (HELENE, 1992).

De acordo com Helene (2005), dentre os processos que interferem na durabilidade do concreto armado, estão processos físicos e químicos, onde os mais relevantes dos processos químicos são a corrosão das armaduras, a penetração de cloretos, a carbonatação, o ataque por sulfatos e as reações álcali-agregado.

No mundo, em aproximadamente 35 países, existem diversas obras com estruturas de concreto afetadas por reação álcali-agregado. Antigamente, quando se falava em reação álcali-agregado, pensava-se em obras de barragem e obras de grande porte. Atualmente as reação podem ser encontradas em diversos tipos de estruturas de concreto por isso os órgãos que estudam o concreto com mais afinco desenvolveram um guia prático para prevenção de reação álcaliagregado, guia prático para inspeção e diagnóstico da reação álcali-agregado e também um guia de ação frente as estruturas afetadas pela reação álcali agregado em conjunto com a ABNT 1557(BATTAGIN, SILVEIRA \& MUNHOZ,2016).

A RAA é um tipo de reação expansiva bastante conhecida devido ao grande número de casos registrados no mundo [3]. A RAA ocorre devido ao processo químico que provém da reação dos compostos mineralógicos do agregado com hidróxidos alcalinos originários do cimento, água de amassamento e agentes externos, os quais estão dissolvidos na solução dos poros de concreto. O produto resultante dessa reação é um gel cristalino expansivo na presença de umidade, podendo originar fissuras, aumento de permeabilidade, diminuição da resistência e consequentemente a ruptura da estrutura. Por trazer tanto risco as obras civis e não havendo um método eficiente na solução desse problema quando instalado a melhor solução técnico/econômica para se combater a RAA é a prevenção (SANCHEZ,KUPERMAN, HELENE, 2008).

Os ensaios, regidos pela norma NBR 15577-1 (ABNT 1555-1, 2008) estabelecem limites de expansão em um determinado corpo-de-prova, concluindo se este é potencialmente reativo ou potencialmente inócuo. A utilização de areia considerada reativa em concreto, somada a um ambiente úmido, geram patologias muitas vezes irreversíveis. A fim de evitar esse problema, adiciona-se material de característica pozolânica que, em algumas quantidades inibem a reação, tornando o agregado que antes era considerado portencialmente reativo, em portencialmente inócuo, conhecido como mitigação.

A deterioração do concreto causada pela reação álcali-agregado foi identificada pela primeira vez no ano de 1940 , na Califórnia - EUA, por Stanton, quando se constatou inexplicáveis expansões em estruturas de diversos prédios escolares, pontes, pavimentos e construções portuárias. Ao investigar, Stanton chegou a conclusão que as expansões estavam relacionadas ao uso de cimento com alto teor de álcalis e que as deteriorações ocorridas foram devido à reação álcali-sílica (HOBBS, 1988).

A reação se manifesta no concreto por um padrão de fissuração, expansão e consequente deslocamento dos elementos estruturais, o que causa ainda a desagregação de fragmentos da superfície. Algumas vezes, ocorre a exsudação de gel sílico-alcalino resultante da reação, que se deposita na superfície do concreto (PAULON, 1981). Segundo Bonato (2015), a reação álcali-agregado, é a reação química que ocorre no interior de uma estrutura de concreto, acontece entre os álcalis do cimento e os minerais dos agregados, sendo que geralmente os álcalis ou hidróxidos alcalinos também podem advir da água de amassamento, de aditivos químicos, de adições pozolânicas, entre outros. A fissuração, é uma porta para agentes prejudiciais ao concreto como o $\mathrm{CO}_{2}$ que age no processo de corrosão das armaduras, ocorre devido à formação de gel que é parcialmente solúvel em água e pode expandir ou contrair com a perda ou ganho de água. Então, a variação de volume ocasiona uma pressão interna e, consequentemente, expansão e fissuração (SILVEIRA, 2007).

Segundo Paulon (1981), independentemente do tipo de reação álcali-agregado (álcali-sílica, álcali-silicato ou álcalicarbonato), a fissuração em forma de mapa pode ser observada em todos os casos, porém algumas características permitem diferenciar os três tipos.

Conforme ilstrado na figura 1, há um bloco de fundação com problema de fissuração devido à reação álcali-agregado em Minas Gerais. 


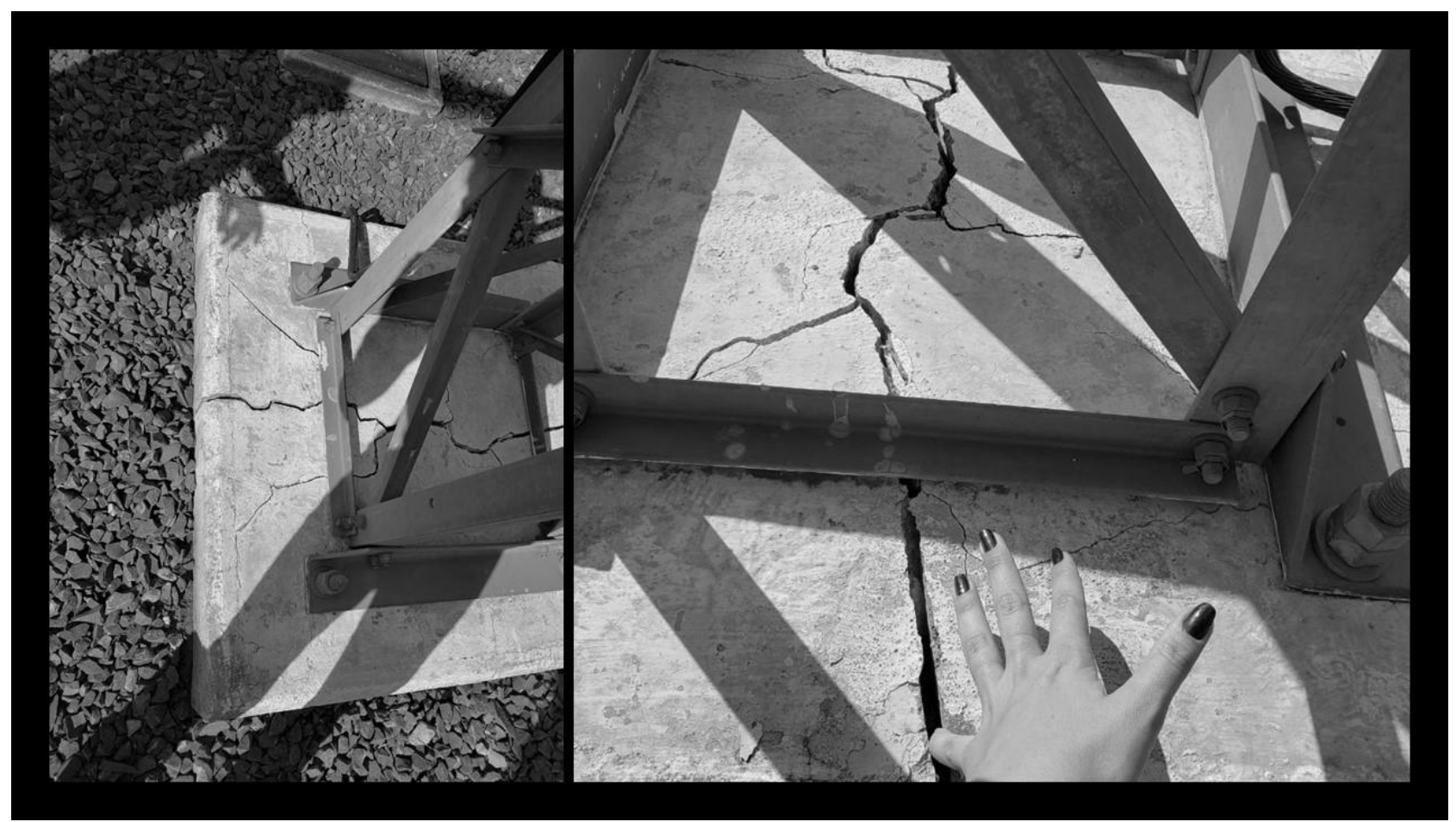

Figura 1: Fissuração de bloco de fundação afetado pela RAA.

Fonte: Autoras(2019).

Vários fatores podem influenciar na intensidade da reação e no seu desenvolvimento no decorrer do tempo, como: a presença de agregado reativo no concreto e de álcalis na pasta de cimento, a presença de umidade e outras condições ambientais. A RAA é mais comum em obras que estejam expostas à umidade.

\section{USO DE ADIÇÕES MINERAIS PARA MITIGAÇÃO DE RAA}

Segundo Mehta (2008), a utilização de adições minerais tem influência benéfica sobre a durabilidade do concreto, devido aos efeitos físicos associados com o tamanho das partículas, que são geralmente mais finas que as do cimento Portland, e pelas reações pozolânicas e cimentíceas.

De acordo com a ASTM C 618/97 e a ABNT NBR 12653: 1992, pozolana é um material que, por si só, possui pouca ou nenhuma atividade cimentícea, porém, quando finamente dividida e na presença de água, reage com o hidróxido de cálcio à temperatura ambiente para formar compostos com propriedades cimentantes, reação na qual é chamada de reação pozolânica.

As pozolanas podem se originar tanto de materiais naturais como: tufos vulcânicos, terras diatomáceas, argilas calcinadas; assim como de subprodutos e resíduos industriais (cinza volante, sílica ativa e cinza de casca de arroz). Elas podem ser utilizadas como substituição de parte do cimento ou como adição em percentuais variáveis em relação à massa de cimento. A adição de materiais pozolânicos, além de combaterem a expansão causada pela reação álcaliagregado, melhora outras propriedades do concreto, como a permeabilidade, a resistência ao calor, a difusividade, e o tamanho da zona de transição, devido à presença de partículas sólidas menores. Existem muitas proposições que buscam explicar o efeito da incorporação de adições minerais pozolânicas na reação álcali-agregado.

A seguir serão apresentadas as diversas explicações de alguns autores sobre a utilização de pozolanas e seus efeitos nestas reações. Vivian (1983); Diamond (1997) e Hobbs (1988) constataram em seus estudos que a incorporação de materiais silicosos finamente moídos, ou pozolanas, poderiam agir de forma benéfica na redução das expansões nas reações álcali-agregado (teores ótimos). Porém, descobriram ainda que alguns teores podem agir de forma contrária, os chamados teores péssimos. Segundo Ramachandran (1998), a eficácia com que as misturas de pozolanas naturais, cinza volante, cinza de casca de arroz, escória de alto forno e sílica ativa previnem os efeitos da reação álcali-agregado, vai depender da composição química das misturas, da quantidade adicionada, do tipo de agregado e do tipo de álcalis no cimento (Sódio, Potássio ou Lítio).

Para um determinado teor de álcalis do cimento, uma determinada quantidade de pozolana deve ser adicionada com o objetivo de produzir uma quantidade máxima de C-S-H e uma quantidade mínima de gel (SILVEIRA, 2007). Segundo Diamond (1997), as adições pozolânicas agem por meio de um mecanismo de reação de superfície, que reduz não só a concentração de álcalis, mas ainda a concentração de íons hidroxila $(\mathrm{OH}-)$, isto é, o pH da solução da água dos poros. Prezzi (1995) explicou que as adições minerais reduzem o pH da solução de água dos poros do concreto, tornando-a 
menos agressiva e diminuem a carga negativa da superfície da sílica. Quanto menor a concentração iônica na superfície carregada da partícula, menores a pressão e as expansões que são desenvolvidas. Chatterji et al. (1989) apontaram como responsável da redução da expansão, o consumo de $\mathrm{Ca}(\mathrm{OH}) 2$ formado durante a hidratação do cimento, sendo a adição de minerais importantes contribuidores para este fato. De acordo com Wang et al. (1991), o Ca(OH)2 possui duas funções no mecanismo da reação álcali-sílica. Age mantendo o pH alto da solução da água dos poros, isto é, uma alta concentração de $\mathrm{OH}$ e age como fonte de $\mathrm{Ca}_{2+}$, cuja liberação pode produzir gel silico-alcalino expansivo. Bhatty (1985) concluiu que as pozolanas reduzem a expansão causada pela reação durante a produção de C-S-H e silicatos hidratados com baixa relação Cálcio/Sílica $(\mathrm{Ca} / \mathrm{Si})$. Estes hidratos podem reter o álcali adicional, reduzindo assim a quantidade de álcalis disponível para a reação com os agregados reativos, eliminando o efeito nocivo da expansão. Os resultados da sua pesquisa indicaram que a quantidade de álcalis retida aumentou com o aumento da adição de pozolanas. A partir dessas considerações, foi possível observar que a adição de pozolana auxilia na redução da expansão do concreto, inibindo desta forma as reações álcali-agregado. A seguir, serão mostrados os principais tipos de adições pozolânicas utilizadas por alguns pesquisadores e seus respectivos efeitos na mitigação das reações álcaliagregado. Duchesne et al. (1994) foram responsáveis por analisar o efeito de algumas adições minerais como sílica ativa, cinza volante e escória de alto forno, com o objetivo de reduzir a expansão devido às reações álcali-agregado. A contribuição das pozolanas foi avaliada por dois parâmetros: consumo de $\mathrm{Ca}(\mathrm{OH})_{2}$ e análise da solução de água dos poros. Os autores chegaram a conclusão que quanto maior o conteúdo de material suplementar (cimento substituído por pozolana), maior o consumo de $\mathrm{Ca}(\mathrm{OH})_{2}$. Não foi constatada nenhuma correlação entre o teor de $\mathrm{Ca}(\mathrm{OH})_{2} \mathrm{e}$ a redução da expansão do concreto. Desta forma, o consumo $\mathrm{Ca}(\mathrm{OH})_{2}$, observado nas análises parece ser apenas uma consequência da reação pozolânica, em função da redução da alcalinidade na solução de água dos po

\section{METODOLOGIA}

Em virtude do histórico encontrado em fundações de subestações na região central de Minas Gerais fez-se um estudo meticuloso para evitar futuros problemas, fazendo uma escolha criteriosa dos agregados encontrados na região da obra. A Figura 2 demonstra a localização das subestações.

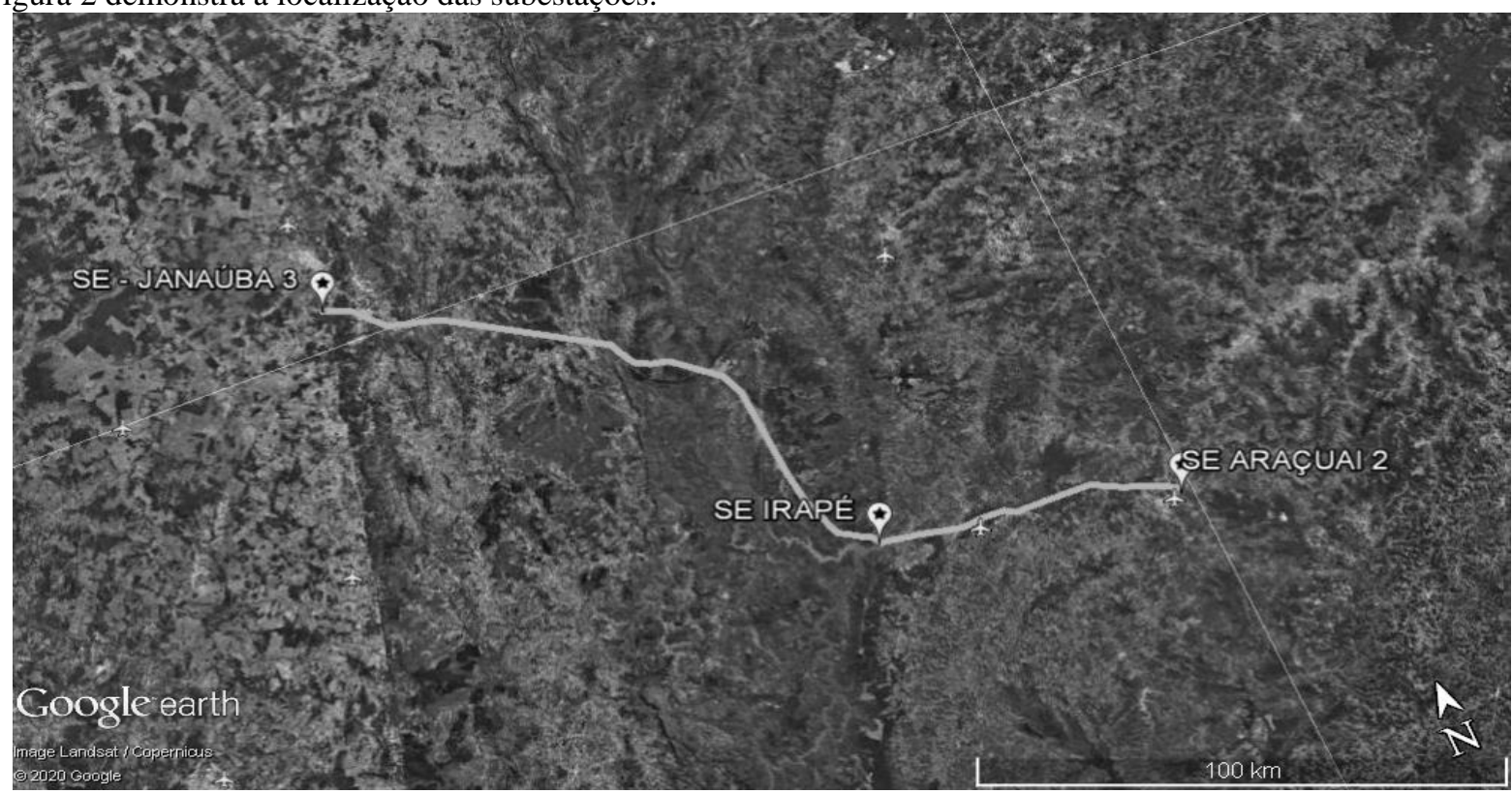

Figura 2: Localização das subestações, a cada $500 \mathrm{~m}$ do traçado há uma torre.

No norte de Minas Gerais há incidência relativamente alta em fundações de subestações e linhas de transmissão então esse estudo teve como objetivo a análise dos materiais de cinco concreteiras da região onde se instalará futura obra prevendo medidas fez-se ensaios de Determinação da Mitigação em Barras de Argamassa pelo Método Acelerado de Reatividade Álcali-Agregado e posterior estudo de traço que possa a vir ser utilizado na obra com materiais selecionados como cimentos com menores teores de álcalis e sílica ativa.

\subsection{Determinação da mitigação da expansão em barras de argamassa pelo método acelerado de reatividade álcali-agregado}




\subsubsection{Agregado, sílica ativa e Cimento Portland}

Nesse estudo foram mapeadas cinco concreteiras nas cidades onde haverá rede de trasnmissão e elas são Caetonópolis, Curvelo(2), Sete Lagoas , Sarzedo. Todas pertencentes ao estado de Minas Gerais. Foram recolhidos os agregados e tipos de cimento de cada concreteira e realizado o estudo de mitigação com a adição de sílica ativa.

Estudos anteriores (relatórios $\mathrm{ABCP}$ ) indicaram que essa região tem agregados potencialmente reativos. Com o intuito de contribuir com subsídios para a mitigação da expansão desses agregados foi realizado o ensaio prescrito pela NBR 15577-5, onde usou os cimentos (CP II E - 40 e CP V), com adição de $8 \%$ de sílica ativa.

Portanto, este relatório apresenta os resultados dos ensaios referentes à determinação da mitigação da expansão em barras de argamassa pelo método acelerado prescrito pela ABNT NBR 15577-5, indicado para avaliar a eficiência de cimentos com adições de materiais pozolânicos ou escórias de alto-forno em inibir a expansão de agregados classificados como potencialmente reativos pela metodologia prescrita pela ABNT NBR 15577-4. O tipo de cimento variou conforme disponibilidade da concreteira.

Os traços utilizados estão expostos na Tabela 1.

Tabela 1 - Traços utilizados para o estudo de mitigação.

\begin{tabular}{|c|c|c|c|c|c|c|c|c|}
\hline \multirow[b]{2}{*}{$\begin{array}{l}\text { Identificação } \\
\text { ensaios }\end{array}$} & \multicolumn{8}{|c|}{ Teores (g) } \\
\hline & $\begin{array}{c}\text { Brita } \\
\text { TOPMIX / } \\
\text { ILCON }\end{array}$ & \begin{tabular}{|c|} 
Brita \\
MASA / \\
PARAO- \\
PEBA
\end{tabular} & \begin{tabular}{|c} 
Brita \\
CITYMI \\
X \\
AGRO- \\
CITY
\end{tabular} & $\begin{array}{c}\text { Brita } \\
\text { LIDER / } \\
\text { AGROCI- } \\
\text { TY }\end{array}$ & $\begin{array}{c}\text { Brita } \\
\text { HMIX / } \\
\text { MON- } \\
\text { TREAL }\end{array}$ & $\begin{array}{c}\text { Cimento } \\
\mathrm{CP} \mathrm{V}\end{array}$ & $\begin{array}{c}\text { Cimento } \\
\text { CP II - E } \\
-40\end{array}$ & $\begin{array}{l}\text { Sílica } \\
\text { Ativa }\end{array}$ \\
\hline $224.498 / 503 / 505 / 8 \%$ & 990,0 & - & - & - & - & 404,8 & - & 35,2 \\
\hline $224.499 / 504 / 505 / 8 \%$ & - & 990,0 & - & - & - & - & 404,8 & 35,2 \\
\hline $224.500 / 503 / 505 / 8 \%$ & - & - & 990,0 & - & - & 404,8 & - & 35,2 \\
\hline $224.501 / 504 / 505 / 8 \%$ & - & - & - & 990,0 & - & - & 404,8 & 35,2 \\
\hline $224.502 / 503 / 505 / 8 \%$ & - & - & 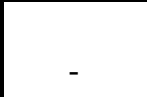 & - & 990,0 & 404,8 & - & 35,2 \\
\hline
\end{tabular}

Fonte: Autoras(2019) 
A Figura 3 detalha os resultados obtidos dos traços executados com os materiais recolhidos das concreteira.

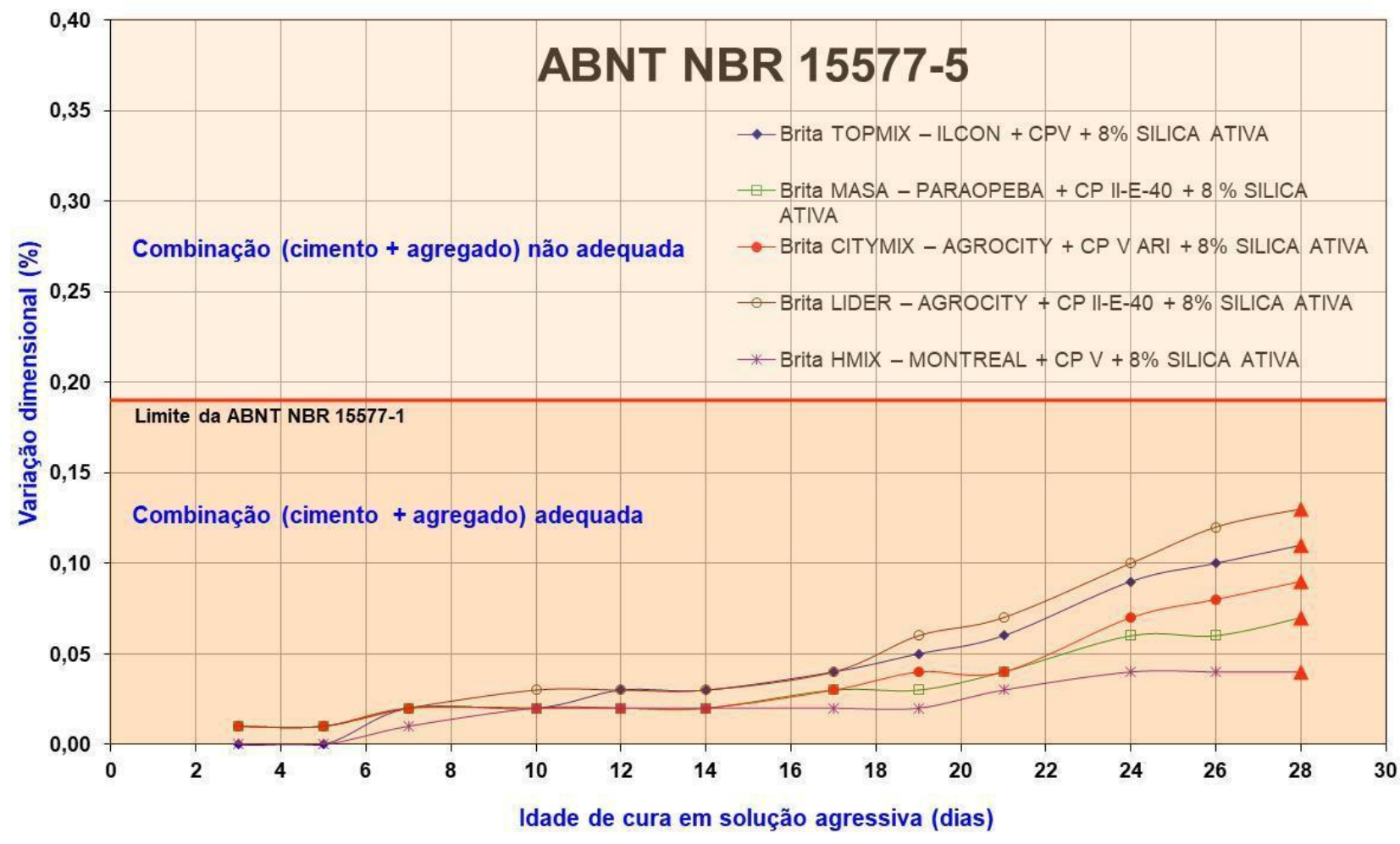

Fonte: Autoras(2019).

Com relação à avaliação da mitigação da reação álcali-agregado pelo método acelerado ABNT NBR 15577-5, a parte 1 da norma estabelece que a comprovação da mitigação da reação é obtida quando a expansão for menor que $0,19 \%$ aos 30 dias (28 dias de cura em solução alcalina).Para valores de expansão iguais ou superiores a $0,19 \%$ são necessários novos ensaios de forma a atender ao limite estabelecido, podendo-se optar por trocar o cimento empregado ou incorporar ou aumentar os teores de materiais inibidores da reação álcali-agregado (pozolana, escória de alto-forno, sílica ativa, metacaulim) ou ainda substituir o agregado.As amostras de brita quando combinadas com os cimentos (CP V e CP II E - $40+8 \%$ de sílica ativa), apresentaram valor de expansão inferior a $0,19 \%$ aos 28 dias de cura em solução alcalina, indicando que as combinações especificamente ensaiadas são adequadas. Os agregados são potencialmente reativos (determinado nos relatórios ABCP 124357, 124358, 124360 e 124363, de 12/09/2019) e os cimentos com adição de $8 \%$ de sílica ativa inibiram a expansão devido à reação álcali-agregado nos níveis requeridos.

\subsubsection{Areia}

A areia utilizada foi a do Rio Paraopeba de Contagem- MG. Os resultados dos ensaios referentes à determinação da reatividade álcali-agregado pelo método preconizado pela ABNT NBR 15577 parte 4 . O método é indicado para avaliar a reatividade de agregados frente a uma solução alcalina de hidróxido de sódio, através da monitorização das expansões dimensionais de barras de argamassa, utilizando-se no ensaio um cimento padrão comprovadamente não inibidor da reação álcali-agregado.

\subsubsection{Dosagem da argamassa}

A Tabela 2 apresenta a composição dos materiais utilizada para a preparação de três barras de argamassa de ( $25 \mathrm{x} 25 \mathrm{x}$ 285) $\mathrm{mm}$. A amostra de areia foi analisada conforme recebida, pois não atendeu a granulometria recomendada em norma. 
TABELA 2 - Composição dos materiais

\begin{tabular}{|l|l|c|}
\hline \multicolumn{1}{|c|}{ Abertura nominal das peneiras (mm) } & Massa (g) \\
\hline \hline \multirow{4}{*}{ Agregado } & $4,8-2,4$ & 99,0 \\
\cline { 2 - 3 } & $2,4-1,2$ & 247,5 \\
\cline { 2 - 3 } & $1,2-0,6$ & 247,5 \\
\cline { 2 - 3 } & $0,6-0,3$ & 247,5 \\
\cline { 2 - 3 } & $0,3-0,15$ & 148,5 \\
\hline \hline Cimento padrão & 440,0 \\
\hline Água destilada $(\mathrm{a} / \mathrm{c}=0,47)$ & 206,8 \\
\hline
\end{tabular}

Fonte: Autoras(2019)

\subsubsection{Cimento padrão}

O cimento padrão utilizado é do tipo CP V-ARI, que obedece integralmente às especificações da ABNT NBR 16697, cujas exigências adicionais da norma ABNT NBR 15577-4 estão registradas na Tabela 3.

TABELA 3 - Características do cimento padrão

\begin{tabular}{|l|c|c|c|}
\hline \multicolumn{1}{|c|}{ Propriedade } & Método de ensaio & Resultado & $\begin{array}{c}\text { Especificação da } \\
\text { ABNT NBR 15577-4 }\end{array}$ \\
\hline \hline Óxido de sódio $\left(\mathrm{Na}_{2} \mathrm{O}\right)$ & ABNT NBR NM 17 & $\mathbf{0 , 3 2} \%$ & - \\
\hline Óxido de potássio $\left(\mathrm{K}_{2} \mathrm{O}\right)$ & ABNT NBR NM 17 & $\mathbf{0 , 8 1} \%$ & - \\
\hline Equivalente alcalino em $\mathrm{Na}_{2} \mathrm{O}^{*}$ & - & $\mathbf{0 , 8 5} \%$ & $(0,90 \pm 0,10) \%$ \\
\hline \hline Área específica Blaine & ABNT NBR 16372 & $\mathbf{4 9 1 0} \mathbf{c m}^{\mathbf{2}} / \mathbf{g}$ & $(4900 \pm 200) \mathrm{cm}^{2} / \mathrm{g}$ \\
\hline Expansibilidade em autoclave & ASTM C 151 & $\mathbf{0 , 1 0 \%}$ & $<0,20 \%$ \\
\hline
\end{tabular}

(*) Equivalente alcalino em $\mathrm{Na}_{2} \mathrm{O} \square \mathrm{Na}_{2} \mathrm{Oeq}=0,658 \% \mathrm{~K}_{2} \mathrm{O}+\% \mathrm{Na}_{2} \mathrm{O}$

Fonte: Autoras(2019). 


\section{СВРAT 2020 \\ concersso ans \\ DE 15 A 17 DE ABRIL | FORTALEZA - CE \\ ISBN 978-65-86819-05-2}

A Tabela 4 apresenta os resultados dos ensaios realizados, destacando-se os valores aos 28 dias de cura em solução de $\mathrm{NaOH} 1 \mathrm{~N}$ a $80^{\circ} \mathrm{C}$.

TABELA 4 - Variação dimensional das barras de argamassa em solução alcalina

\begin{tabular}{|c|c|}
\hline $\begin{array}{l}\text { Idade de Cura agressiva } \\
\qquad{\text { (dias })^{(*)}}^{(*)}\end{array}$ & $\begin{array}{c}\text { Variações dimensionais } \\
\text { médias }(\%)\end{array}$ \\
\hline 1 & - \\
\hline 2 & 0,01 \\
\hline 3 & - \\
\hline 4 & - \\
\hline 5 & 0,01 \\
\hline 6 & - \\
\hline 7 & 0,02 \\
\hline 8 & - \\
\hline 9 & 0,03 \\
\hline 10 & - \\
\hline 11 & - \\
\hline 12 & 0,04 \\
\hline 13 & - \\
\hline 14 & 0,05 \\
\hline 15 & - \\
\hline 16 & 0,05 \\
\hline 17 & - \\
\hline 18 & - \\
\hline 19 & 0,05 \\
\hline 20 & - \\
\hline 21 & 0,05 \\
\hline 22 & - \\
\hline 23 & 0,06 \\
\hline 24 & - \\
\hline 25 & - \\
\hline 26 & 0,08 \\
\hline 27 & - \\
\hline 28 & 0,08 \\
\hline
\end{tabular}

- = leitura não realizada

Fonte: autoras(2019).

(*) Para conhecer a idade do ensaio desde a moldagem acrescentar 2 dias. 
A Figura 4 ilustra a evolução das expansões médias das barras de argamassa com o tempo de cura.

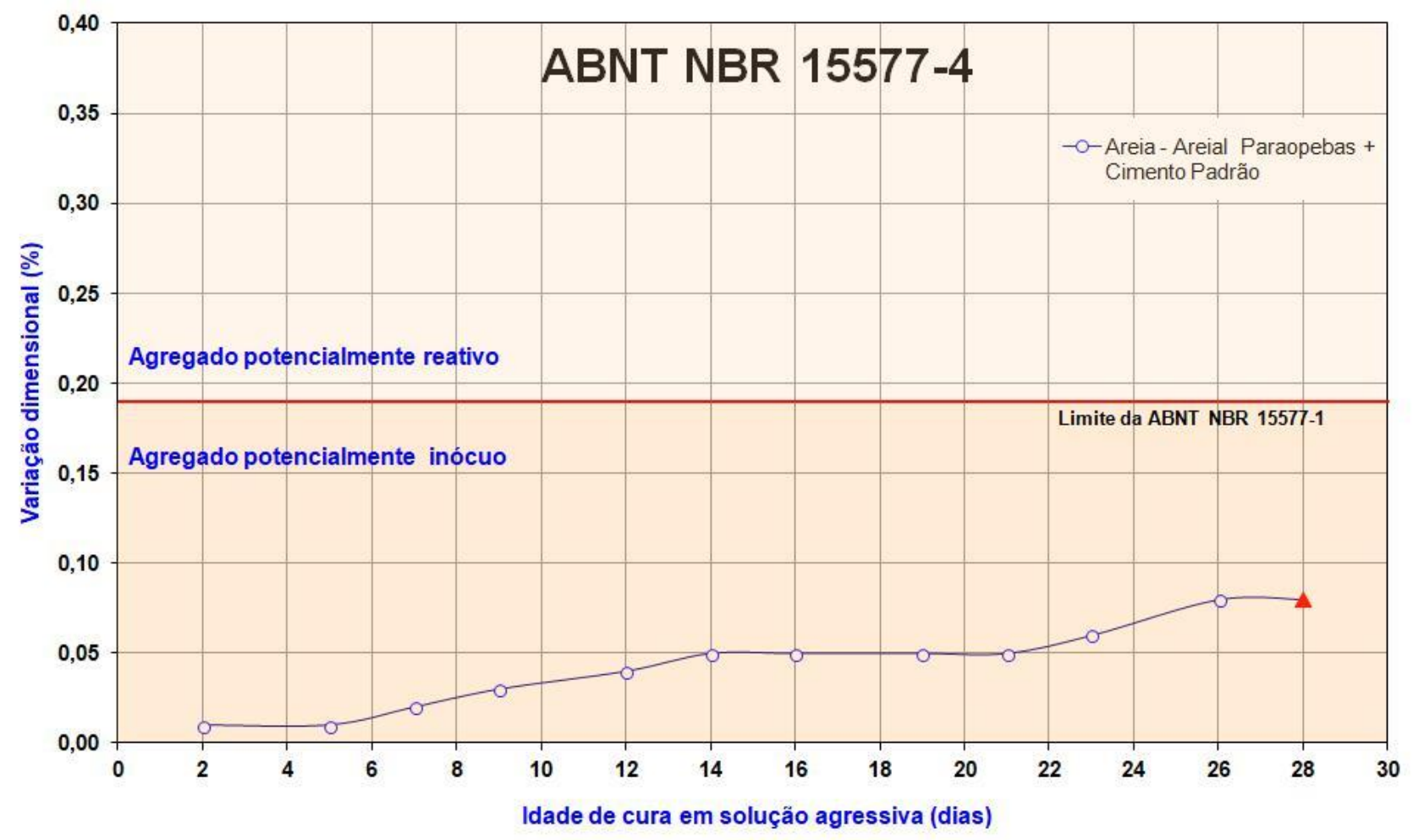

Figura 4 - Evolução das expansões médias das barras de argamassa com o tempo de cura. Fonte:autoras.

De acordo com a norma ABNT NBR 15577-1, quando o resultado do ensaio acelerado pela ABNT NBR 15577-4 indicar expansão menor que $0,19 \%$ aos 30 dias (28 dias de cura em solução alcalina) o agregado é considerado potencialmente inócuo para uso em concreto. Expansão maior ou igual a $0,19 \%$ indica que o agregado é potencialmente reativo.De acordo com os resultados apresentados, observa-se que o valor médio de expansão das barras de argamassa aos 28 dias de cura em solução alcalina da amostra de Areia - Rio Paraopeba - Areial Paraopebas - Contagem/MG foi de $0,08 \%$, indicando que o agregado é potencialmente inócuo (grau R0) segundo os critérios estabelecidos.

O engenheiro Arnaldo Battagin em “A reação álcali-agregado: causas, diagnóstico e soluções” relatou um histórico de ensaios da ABCP em todos os estados do Brasil, a região de estudo desse artigo Minas Gerais apresentou 58 análises realizadas no ano de 2016, é um dos estados com poucos ensaios realizados comparados com São Paulo que foi 532 e Pernanbuco que foi 228.

A Tabela 5 apresenta algumas medidas recomendadas pelo autor onde foi dividido em intensidade de açãó preventiva em desnecessário, mínima, moderada e forte. 
Tabela 5 - Medidas recomendadas

\begin{tabular}{|c|c|c|}
\hline $\begin{array}{l}\text { Intensidade da } \\
\text { ação preventiva }\end{array}$ & $\begin{array}{l}\text { Grau de reatividade potencial do } \\
\text { agregado }\end{array}$ & Medida mitigadora \\
\hline Desnecessária & Inócuo & \\
\hline Mínima & Reativo Grau 1 & 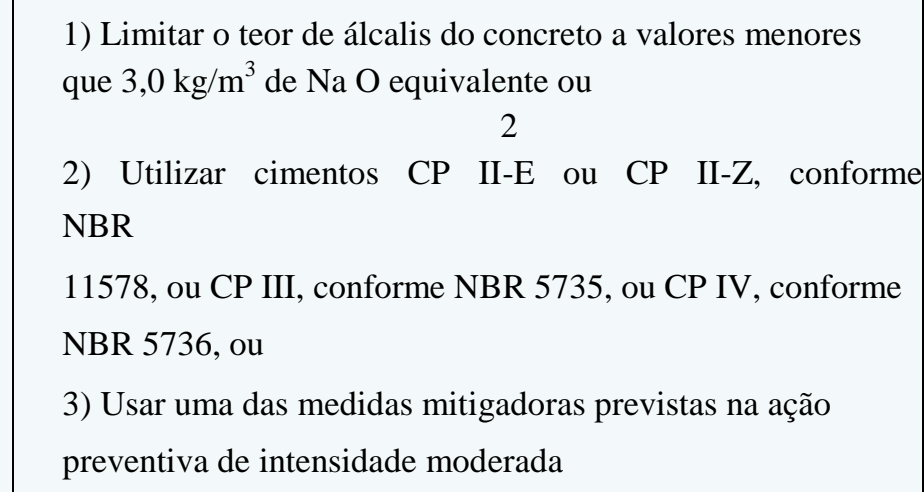 \\
\hline Moderada & Reativo Grau 2 & $\begin{array}{l}\text { 1) Limitar o teor de álcalis do concreto a valores menores } \\
\text { que } 2,4 \mathrm{~kg} / \mathrm{m}^{3} \mathrm{Na} \mathrm{O} \text { equivalente ou } \\
\qquad 2 \\
\text { 2) Utilizar cimento CP III, com no mínimo } 60 \% \text { de escória } \\
\text { conforme NBR } 5735 \mathrm{ou} \\
\text { 3) Utilizar cimento CP IV com no mínimo } 30 \% \text { de pozolana } \\
\text { conforme NBR } 5736 \text { ou } \\
\text { 4) Usar uma das medidas mitigadoras previstas na ação } \\
\text { preventiva de intensidade forte }\end{array}$ \\
\hline Forte & Reativo Grau 3 & $\begin{array}{l}\text { 1) Utilizar materiais inibidores da reação de acordo com a } \\
\text { tabela } 3 \text {, comprovando a mitigação da reatividade potencial } \\
\text { por ensaio ou } \\
\text { 2) Substituir o agregado em estudo. }\end{array}$ \\
\hline
\end{tabular}

\section{Fonte: BATTAGIN(2010)}

$\mathrm{O}$ autor ainda recomenda incorporar na norma a classificação dos agregados quanto ao grau de reatividade potencial e assim orientar com mais detalhe os usuários quanto à intensidade das medidas de mitigação.

\section{Conclusão}

Os resultados dos ensaios acelerados de RAA (NBR 15577/2018) permitiram concluir que a sílica ativa e o tipo de cimento inertizou as misturas, influenciou de forma significativa as expansões provenientes da reação álcali-agregado. $\mathrm{O}$ aumento da pozolanicidade dos cimentos contribuiu de forma relevante para a mitigação e/ou inibição da incidência da reação álcali-agregado nas misturas investigadas como pode ser observado nos traços onde foi utilizado CP II - E 40. O melhor desempenho segundo a Norma 15577/2018 foi a Brita H-mix-Montreal e Cimento CPV $+8 \%$ de sílica ativa. 


\section{Referências bibliográficas}

ASSOCIAÇÃO BRASILEIRA DE NORMAS TÉCNICAS. NBR 15577-1, agregados - Reatividade álcali-agregado Parte 1: Guia para avaliação da reatividade potencial e medidas preventivas para uso de agregados em concreto, 2008. ABNT NBR 15577-1/18 Agregados - Reatividade álcali-agregado - Parte 1: Guia para avaliação da reatividade potencial e medidas preventivas para uso de agregados em concreto

ABNT NBR 15577-4/18 Agregados - Reatividade álcali-agregado - Parte 4: Determinação da expansão em barras de argamassa pelo método acelerado

ABNT NBR 16372/15 Cimento Portland - Determinação da finura pelo método de permeabilidade ao ar (Método de Blaine)

ABNT NBR 16697/18 Cimento Portland - Requisitos

ABNT NBR NM 17/12 Cimento Portland - Análise química - Método de arbitragem para a determinação de óxido de sódio e óxido de potássio por fotometria de chama.

ASSOCIAÇÃO BRASILEIRA DE NORMAS TÉCNICAS. NBR 15577-1, agregados - Reatividade álcali-agregado Parte 1: Guia para avaliação da reatividade potencial e medidas preventivas para uso de agregados em concreto, 2008.

BAtTAgin, A.; SILVeIRA, A.L.; MUNHOZ, F.; BAtTAgin, I. Associação Brasileira de Cimento Portland. A evolução da cultura da prevenção da reação álcali-agregado no mercado nacional. In: Concreto e construç̃es. Ano 44. Ed. Ibracon, Jul-Set 2016.

BHATTY, M. S. Y.. Mechanism of pozzolanic reactions and control of alkali-aggregate expansion. Cement, Concrete and Aggregates, West Conshohocken, v.7, n.2, 1985.

CARASEK, H.; CASCUDO, O.; CAETANO, G. Contribuição à previsão de danos para estruturas de concreto atacadas pela reação álcali-silica. In: Concreto e construções. Ano 44. Ed. Ibracon, Jul-Set 2016.

CHATTERJI, S.; THAUlOW, N.. Studies on alkali-silica reaction. Cement and Concrete Research, West Conshohocken, 1989.

DAHER, C. H. S. Avaliação do grau de influência de parâmetros de contorno no ensaio de reatividade potencial álcaliagregado pelo método acelerado. Dissertação (Mestrado), Universidade Federal do Paraná, Curitiba, 2009.

DIAMOND, S.. Alkali Silica Reactions: Some Paradoxes. Cement and Concrete Composites, Amsterdã, v.19, 1997. DUCHESNE, J.; BÉRUBÉ, M. A.. The effectiveness of suplementary cementing materials in supressing expansion due to ASR: another look at the reaction mechanism: pore solution chemistry. Cement and Concrete Research, West Conshohocken, v.24, n.2, 1994.

DUCHESNE, J.; BÉRUBÉ, M.A.. The effectiveness of suplementary cementing materials in supressing expansion due to ASR: another look at the reaction mechanism: concrete expansion and portlandite depletion. Cement and Concrete Research, West Conshohocken v.24, n.1, 1994.

FUSCO, P.B.. Estruturas de Concreto. São Paulo: McGraw-Hill do Brasil, v.1, 1976.

GLASSER, L. S. D.; KATAOKA, N.. The chemistry of alkali-aggregate reaction. Cement and Concrete Research, West Conshohocken, v.11, 1981.

HASPARYK, N. P.. Investigação de concretos afetados pela reação álcali-agregado e caracterização avançada do gel exsudado. Tese (Doutorado em

FRAGA, Y. S. B.; SILVA, C. M. M. A.. Efeitos de adições minerais para mitigação de reações álcali-agregado no concreto: estado da arte. Engineering Sciences, v.5, n.1, p.1-13, 2017. 
HELENE, P.. Manual de Reparo, Proteção e Reforço de Estruturas de Concreto. São Paulo: Editora Rehabilitar, 2005. HELENE, P.. Manutenção para Reparo, Reforço e Proteção de Estruturas de Concreto. 2 ed. São Paulo: Pini, 1992.

HOBBS, D. W.. Alkali-silica reaction in concrete. London: 1988.

MEHTA, P. K.. Concreto Sustentável. Revista Téchne. São Paulo: 2008.

PREZZI, M.. Analysis of the Mechanism of Concrete Deterioration. Berkeley: University of California, 1995.

RAMACHANDRAN, V. S.. Alkali-aggregate expansion inhibiting admixtures. Cement and Concrete Composites, Amsterdã, v.20, n.3, 1998.

SANCHEZ, L., KUPERMAN, S., HELENE, P. Reação álcali-agregado - Método Acelerado Brasileiro de Prismas de Concreto (ABCPT). Anais de 50 Congresso Brasileiro do Concreto - CBC2008 - 50CBC0223, 2008.

SILVEIRA, A. A.. Contribuição ao estudo do efeito da incorporação de cinza de casca de arroz em concretos Efeitos de adições minerais para mitigação de reação álcali-agregado. Tese (Doutorado) - Universidade Federal do Rio Grande do Sul, Porto Alegre, 2007.

VIVIAN, H. E.. The process of alkali-aggregate reaction. Proceedings. Alkali in Cement and Concrete. London: 1983. WANG, H.; GILLOTT, J. E.. Mechanism of alkali-silica reaction and the significance of calcium hydroxide. Cement and Concrete Research, West Conshohocken, v.21, 1991. 